\title{
Mortality rates amongst mice with endogenous septicaemia caused by Pseudomonas aeruginosa isolates from various clinical sources
}

\author{
N. FURUYA, Y. HIRAKATA*, K. TOMONO†, T. MATSUMOTO, K. TATEDA*, M. KAKU \\ and K. YAMAGUCHI*
}

Department of Laboratory Medicine, Nagasaki University School of Medicine, Nagasaki 852; * Department of Microbiology, Toho University School of Medicine, Tokyo 143 and $\dagger$ Department of Pulmonary Medicine, Jichi Medical School, Tochigi 329-04, Japan

\begin{abstract}
Summary. Mice that had been treated with cyclophosphamide and ampicillin were fed with Pseudomonas aeruginosa. These procedures induced an endogenous septicaemia under conditions mimicking the pathophysiology of the disease in man. This model was used to compare the mortality rates in mice infected with $P$. aeruginosa isolates from various clinical sources. Mortality rates in mice given isolates from blood cultures had a broad range $(0-100 \%)$, but the mean rate was significantly higher than with isolates from other infection sites. Moreover, blood isolates persisted in the intestines of mice after oral inoculation, whereas most isolates from other sources were gradually eliminated. Most $P$. aeruginosa isolates from blood culture produced significantly higher levels of exotoxin A and total proteases than isolates from other infection sites. Amongst the blood isolates, all but one of the lethal strains produced large quantities of exotoxin A or total proteases or both. Taken together, the results suggest that the ability of $P$. aeruginosa to adhere to the intestinal tract and to produce high levels of exo-enzymes may contribute to the development of fatal septicaemia.
\end{abstract}

\section{Introduction}

The mortality rate for septicaemia caused by gramnegative bacteria remains high in immunocompromised patients, despite the availability of various potent broad-spectrum antimicrobial agents. ${ }^{1,2}$ Most septicaemias in immunocompromised patients arise as a result of invasion by the endogenous microflora, particularly that of the gastro-intestinal tract. ${ }^{3,4}$

Amongst gram-negative bacilli causing septicaemia, $P$ seudomonas aeruginosa has been associated with the highest mortality rates ${ }^{5,6} \mathrm{We}$ reported previously that $P$. aeruginosa also gives a high mortality rate in leukopaenic mice with endogenous bacteraemia. ${ }^{7} P$. aeruginosa also causes severe infections in patients with burns, malignant tumours, cystic fibrosis and other diseases. ${ }^{8}$

$P$. aeruginosa has several toxic cellular components, notably lipopolysaccharide, and manufacturers extracellular products such as proteases and exotoxins, that account for its virulence in these patients. ${ }^{9,10}$ Recent investigations have indicated that proteases may play an important role in the establishment and maintenance of various types of pseudomonal infections. ${ }^{11}$

Received 18 Nov. 1992; revised version accepted 6 Jan. 1993.
However, the significance of these exo-enzymes in septicaemia remains unclear.

In this study, septicaemia was caused in leucopaenic mice fed with $P$. aeruginosa cultures. Unlike conventional infections models, which usually employ intraperitoneal or intravenous infection routes, this model incorporated the steps of bacterial colonisation, overgrowth and invasion, and consequently closely mimicked the pathophysiology of septicaemia in man. ${ }^{12,13}$ With this model, the mortality rates for $P$. aeruginosa strains obtained from various clinical sources were evaluated, as was the relationship between the mortality rate and the ability of the bacteria to survive in the intestinal tract and produce exotoxin $\mathrm{A}$, proteases, elastase and phospholipase $\mathrm{C}$ in vitro.

\section{Materials and methods}

\section{Bacteria}

Thirty-five $P$. aeruginosa isolates obtained at Nagasaki University Hospital, Nagasaki, Japan were used (table I); 17 isolates were from blood, 12 from sputum, three from urine and one each from ascites, pus and other secretion. $P$. aeruginosa $\mathrm{D} 4,{ }^{7}$ which was isolated from the cardiac blood of a mouse with 
Table I. Clinical sources and serotypes of $P$. aeruginosa isolates

\begin{tabular}{lcl}
\hline Source & Serotype & \multicolumn{1}{c}{ Strain no. } \\
\hline Blood & A & B2, B4, B5, B8, B11, B16 \\
& B & B9, B12, B13, B14, B17 \\
& E & B10 \\
& G & B6, B15 \\
& M & B3 \\
Sputum & Non-typable & B1, B7 \\
& A & S5, S7 (mucoid), S8, \\
& B & S10 (mucoid), S11 \\
& E & S1, S12 \\
& F & S6 \\
& G & S4 \\
& M & S3 \\
Urine & Non-typable & S9 (mucoid) \\
& A & U1 \\
& I & U2 \\
Other sites & Non-typable & U3 \\
& A & O1, O2 \\
& E & O3 \\
\hline
\end{tabular}

systemic bacteraemia, was also used. This strain consistently caused a $70-90 \%$ mortality rate in the model of endogenous septicaemia used.

Bacteria were identified with Vitek Gram-Negative Identification Cards (Vitek System Inc., Hazelwood, MO, USA). Serotypes were determined by agglutination with monoclonal antibodies (Mel-Assay; Meiji Seika Kaisha, Ltd, Tokyo, Japan).

Stock bacterial cultures were suspended in Mueller Hinton Broth (Difco) containing glycerol 30\%, and stored at $-80^{\circ} \mathrm{C}$ until required.

\section{Establishment of endogenous septicaemia}

A previously described model of endogenous septicaemia was used, but with some modification. ${ }^{13}$ Pathogen-free male ddY mice (Japan SLC Inc. Ltd, Shizuoka, Japan) weighing $20-24 \mathrm{~g}$ were housed in sterile plastic cages with filter hoods and given a sterile diet and distilled water ad libitum. They were given sodium ampicillin (Viccillin; Meiji) $200 \mathrm{mg} / \mathrm{kg}$ daily by intraperitoneal injection on days $1-5$ to disturb the normal intestinal flora and aid colonisation by $P$. aeruginosa. Cyclophosphamide (Endoxan; Shionogi and Co., Ltd, Osaka, Japan) was given intraperitoneally at a dose of $250 \mathrm{mg} / \mathrm{kg}$ on days 6 and 9 . This dose of cyclophosphamide induced leucopaenia $\left(<1000\right.$ leucocytes $\left./ \mathrm{mm}^{3}\right)$ without lethality in the absence of infection.

Bacteria were grown overnight at $37^{\circ} \mathrm{C}$ on Trypticase Soy Agar (BBL Microbiology Systems), then suspended in sterile saline $0.45 \%$. The density of the suspension was adjusted to $10^{7} \mathrm{cfu} / \mathrm{ml}$ by reference to a standard curve relating optical density (OD) and bacterial count. The bacterial suspension was given to the mice in their drinking water on days $2-4$. The mice were examined twice daily, and deaths were recorded until day 16.

\section{Quantitation of faecal $P$. aeruginosa in mice}

Before the start of the study, faecal specimens from the mice were examined to confirm the absence of $P$. aeruginosa. Fresh faecal pellets were also collected from each mouse on days 6 and 10. Each sample was weighed, suspended and diluted in saline, then plated on agar containing nalidixic acid $15 \mathrm{mg} / \mathrm{L}$ and cetrimide $200 \mathrm{mg} / \mathrm{L}$ (NAC Agar; Eiken Chemical Co. Ltd, Tokyo, Japan) for selection of $P$. aeruginosa. After incubation for $24 \mathrm{~h}$ at $37^{\circ} \mathrm{C}$, the plate counts were recorded as cfu of $P$. aeruginosa/g of faeces.

\section{Exo-enzyme assays}

Exotoxin A. Trypticase Soy Broth (BBL) dialysate (TSBD-C) was used as the growth medium for the measurement of exotoxin A. ${ }^{14,15}$ The iron content the medium after treatment with Chelex (BioRad) was $0 \cdot 1 \mathrm{mg} / \mathrm{L}$, as determined with bathophenanthroline. ${ }^{16}$

Bacteria were incubated in TSBD-C for $24 \mathrm{~h}$ at $32^{\circ} \mathrm{C}$ with vigorous shaking. After centrifugation at $3000 \mathrm{~g}$, the supernates were passed through a $0 \cdot 22-\mu \mathrm{m}$ pore filter and then assayed by an enzyme-linked immunosorbent assay (ELISA) similar to that described previously. ${ }^{16}$ Briefly, microtitration plates were first coated with goat anti-exotoxin $\mathrm{A}$ antiserum (List Biological Laboratories Inc., CA, USA). Culture supernates, or serial dilutions of purified $P$. aeruginosa exotoxin A (List) $(0.0031-12.5 \mathrm{mg} / \mathrm{L}$ in TSBD-C broth), were then added. Rabbit antiserum against $P$. aeruginosa exotoxin A (a gift from Sumitomo Chemical Co. Ltd, Tokyo, Japan) was used as a second antibody. Alkaline phosphatase-labelled goat antirabbit IgG antibodies (E-Y Laboratories Inc., San Mateo, CA, USA) were then added, followed by the reaction substrates detailed previously. ${ }^{16}$

Protease assays. Total proteolytic activity was measured by the method of Woods et al. ${ }^{17}$ Organisms were grown for $24 \mathrm{~h}$ at $37^{\circ} \mathrm{C}$ in Brain Heart Infusion Broth (Difco) with vigorous mixing. Subsequently, $0 \cdot 5-\mathrm{ml}$ amounts of the culture supernates were diluted

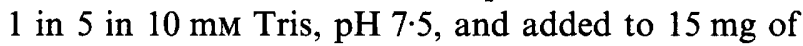
hide powder azure (Sigma) as a substrate. The mixture was incubated at $37^{\circ} \mathrm{C}$ for $1 \mathrm{~h}$, with vigorous shaking. Undissolved substrate was removed by centrifugation at $3000 \mathrm{~g}$ for $10 \mathrm{~min}$. $\mathrm{OD}_{595}$ values of the supernates were then compared with a standard curve prepared by treating the substrate for the same period with purified $P$. aeruginosa protease (Nagase Biochemicals Ltd., Kyoto, Japan) at enzyme concentrations of $0.0075-15.63 \mathrm{mg} / \mathrm{L}$.

The assay method for elastase activity was identical to that for total protease, except that: (i) the culture supernates were diluted three-fold; (ii) $10 \mathrm{mg}$ of elastin Congo red (Sigma) was used as a substrate and (iii) $\mathrm{OD}_{495}$ was recorded. Values were compared with those of a standard curve derived with purified $P$. aeruginosa elastase (Nagase) at concentrations of $0.49-125 \mathrm{mg} / \mathrm{L}$.

Phospholipase $C$. Organisms were grown in tryptose 


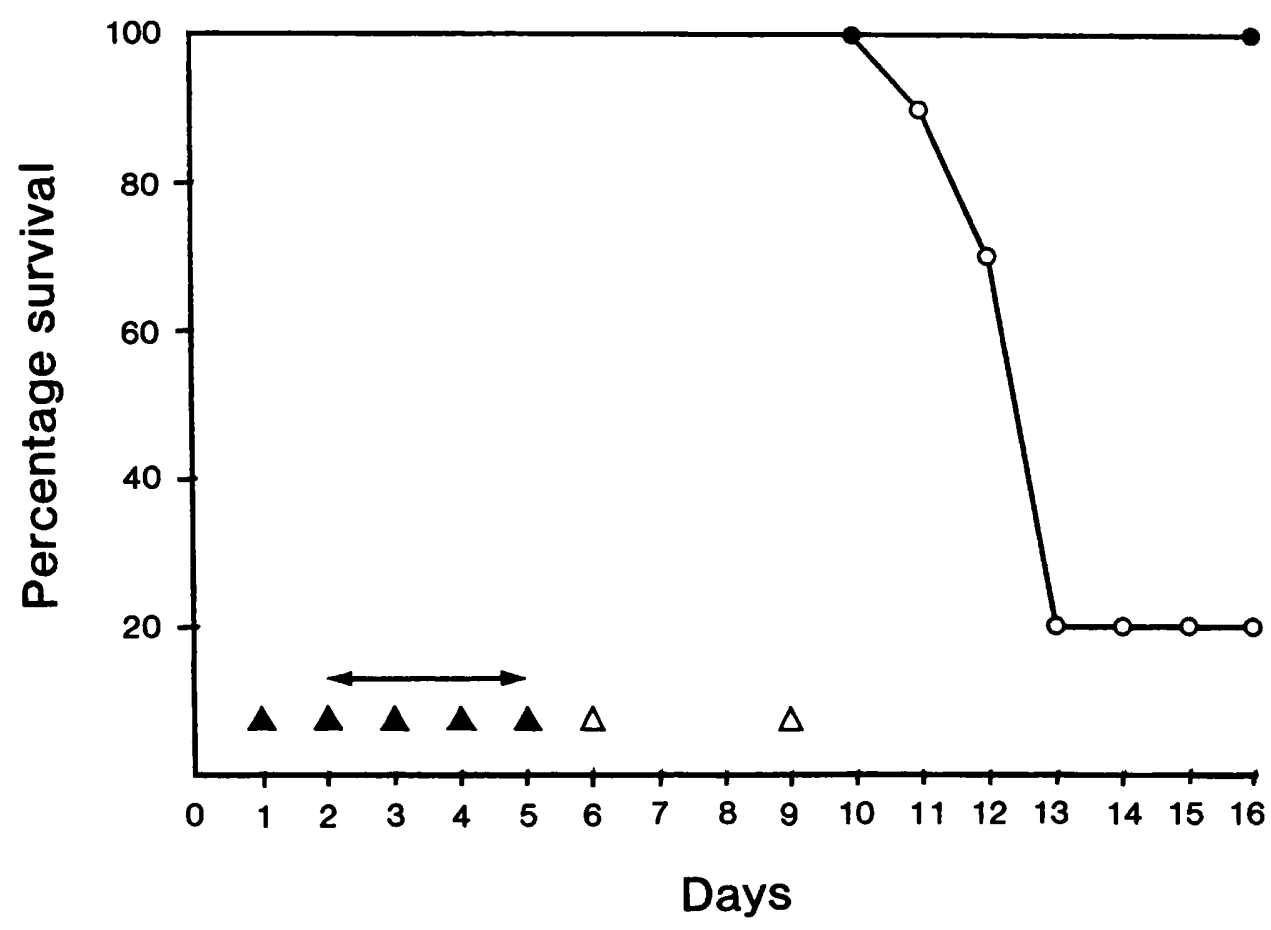

Fig. 1. Survival of leucopaenic mice in the presence or absence of an oral bacterial challenge. Groups of 10 mice were given ampicillin $200 \mathrm{mg} / \mathrm{kg}$ by intraperitoneal injection daily on days $1-5(\Delta)$, and cyclophosphamide $250 \mathrm{mg} / \mathrm{kg}$ on days 6 and $9(\triangle)$. P. aeruginosa D4 was given orally with drinking water on days $2-4(\leftrightarrow)$. $\bigcirc$, mice with bacterial challenge; $\boldsymbol{\bullet}$, unchallenged control mice.

minimal medium ${ }^{18}$ at $32^{\circ} \mathrm{C}$ for $24 \mathrm{~h}$, whilst being shaken vigorously. Phospholipase $\mathrm{C}$ activity was measured by the method of Berka et al.$^{19}$ with minor modifications. Ten $\mathrm{mg}$ of decolourising carbon (Nacalai Tesque Inc., Kyoto, Japan) was added to $1 \mathrm{ml}$ of culture supernate to remove interfering pigment. After centrifugation to deposit the carbon, 20- $\mu$ l amounts of supernate were added to $180-\mu \mathrm{l}$ amounts of a solution containing $250 \mathrm{~mm}$ Tris- $\mathrm{HCl}$ buffer (pH 7.2), glycerol $60 \%, 1.0 \mu \mathrm{M} \mathrm{ZnCl}_{2}$ and $10 \mathrm{~mm} p$ nitrophenylphosphorylcholine (Sigma) in the wells of a microtitration plate. The plate was incubated at $37^{\circ} \mathrm{C}$ for $90 \mathrm{~min}$ and the $\mathrm{OD}_{405}$ values were read with a microplate reader. Values were compared with those of a standard curve prepared with purified Clostridium perfringens phospholipase $\mathrm{C}$ (Sigma) at concentration of $0.625-80 \mathrm{U} / \mathrm{mL}^{16}$

\section{Statistical tests}

Student's $t$ test was used to compare means; $\mathrm{p}<0.05$ was considered to be significant.

\section{Results}

Mortality rates among mice with experimental endogenous septicaemia

Without an oral challenge with bacteria, no deaths occurred up to day 16 amongst mice treated with cyclophosphamide and ampicillin. By contrast, the mortality rate amongst leucopaenic mice given $P$.
Table II. Comparison of mortality rates amongst mice with experimental endogenous septicaemia

\begin{tabular}{lcl}
\hline Source & Mortality rate $(\%)$ & \multicolumn{1}{c}{ Strain no. } \\
\hline Blood & 0 & B1, B2, B3, B4 \\
& 20 & B5, B6 \\
& 30 & B7 \\
& 70 & B8 \\
& 80 & B9, B10, B11 \\
Sputum & 90 & B12 \\
& 100 & B13, B14, B15, B16, B17 \\
Urine & 0 & S1, S3, S4, S5, S6, S7, \\
Other sites & 10 & S8, S9, S10, S11, S12 \\
& 0 & S2 1, U2, U3 \\
& 0 & O1, O2, O3 \\
\hline
\end{tabular}

${ }^{*}$ Results are for groups of 10 mice.

aeruginosa D4 was eight out of 10 . These mice died between days 11 and 13 with systemic bacteraemia caused by the challenge strain (fig. 1).

Table II shows the mortality rates for groups of 10 mice challenged with each of $35 P$. aeruginosa isolates. The mortality rates ranged widely amongst isolates from blood cultures: with isolates B1, B2, B3 and B4, no deaths were observed up to day 16 , whereas isolates $\mathrm{B} 13, \mathrm{~B} 14, \mathrm{~B} 15, \mathrm{~B} 16$ and $\mathrm{B} 17$, gave $100 \%$ mortality, with deaths occurring on days 11-14. Deaths were associated with systemic bacteraemia caused by the challenge strain. In contrast, no deaths occurred in 17 of 18 groups of mice given isolates from other infection sites besides blood. In the one group given a sputum isolates (S2) one of 10 mice died. The mean mortality rates amongst mice given isolates from blood, sputum, 


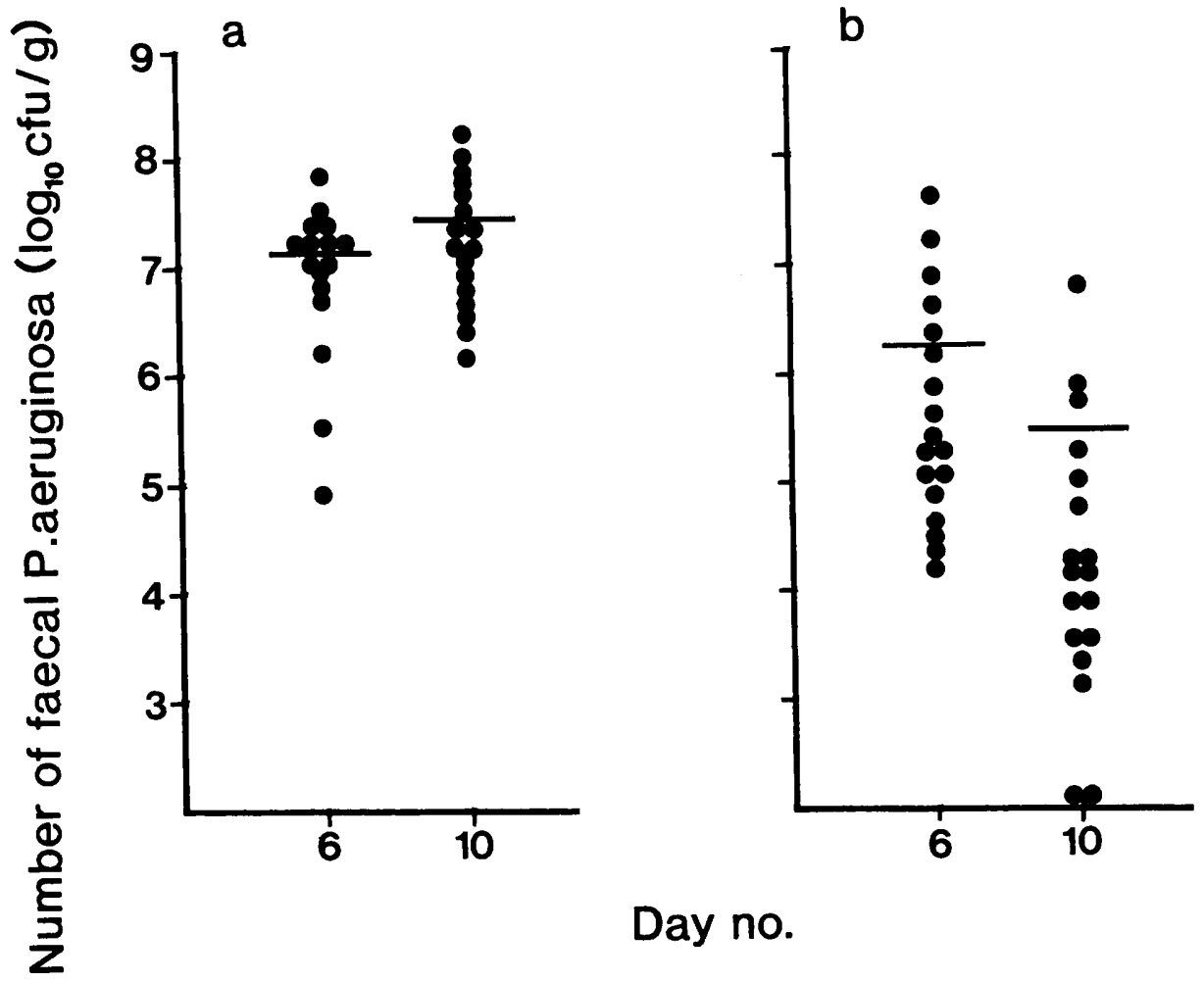

Fig. 2. Quantification of faecal P. aeruginosa in mice with experimental endogenous septicaemia after oral inoculation. Mice were treated as described in fig. 1. Results are for a, 17 groups each comprising five mice inoculated with different blood isolates; $\mathbf{b}, 18$ groups each of five mice inoculated with isolates from other sources. The points show the means within each group and the horizontal bars show the means for all groups.

Table III. Comparison of in-vitro exo-enzyme production by $P$. aeruginosa isolates from various clinical sources

\begin{tabular}{l|cccc}
\hline \multirow{2}{*}{ Source } & \multicolumn{4}{|c}{ Mean (SEM) concentration in culture supernate of } \\
\cline { 2 - 5 } & $\begin{array}{c}\text { exotoxin A } \\
(\mathrm{mg} / \mathrm{L})\end{array}$ & $\begin{array}{c}\text { total protease } \\
(\mathrm{mg} / \mathrm{L})\end{array}$ & $\begin{array}{c}\text { elastase } \\
(\mathrm{mg} / \mathrm{L})\end{array}$ & $\begin{array}{c}\text { phospholipase C } \\
(\mathrm{U} / \mathrm{ml})\end{array}$ \\
\hline Blood & $1.40(0.58)^{*}$ & $32.07(10.81)^{*}$ & $12.30(3.38)^{*}$ & $33.34(5.63)$ \\
Sputum & $0.05(0.01)$ & $1.67(0.48)$ & $25.31(7.81)^{*}$ & $20.91(3.83)$ \\
Urine & $0.11(0.02)$ & $1.81(0.54)$ & $4.47(0.11)$ & $28.11(5.67)$ \\
Other sites & $0.09(0.04)$ & $0.97(0.64)$ & $6.12(0.59)$ & $55.40(11.87)$ \\
\hline
\end{tabular}

* Significantly higher than for isolates from other sources $(\mathrm{p}<0.05)$.

urine and other infection sites were $57,0 \cdot 8,0$ and $0 \%$, respectively. The higher mortality rate amongst mice given blood isolates was significant $(\mathrm{p}<0 \cdot 01)$.

\section{Quantification of faecal $P$. aeruginosa}

In the mice given blood-culture isolates or strain D4, the number of $P$. aeruginosa cells persisted at $>10^{5} \mathrm{cfu} / \mathrm{g}$ faeces on day 10 (fig. $2 \mathrm{a}$ ). In contrast, the numbers of faecal pseudomonas tended to decrease with time when isolates from other sources were used (fig. 2b). However, exceptions to this latter pattern arose with isolates S2, S3, S6, S9 and U3. When averaged, the faecal counts for blood isolates were significantly higher than those for isolates from other sources on day $10\left(5.0 \times 10^{7}\right.$ versus $\left.5.5 \times 10^{5} ; \mathrm{p}<0.01\right)$.
Quantification of in-vitro production of $P$. aeruginosa exo-enzymes

Differences in mean exo-enzyme levels were found between $P$. aeruginosa strains isolated from different infection sites (table III). On average, $P$. aeruginosa isolates from blood produced higher levels of exotoxin A and total proteases than strains from any other sites ( $p<0.05$ for both enzymes). Moreover, strains from blood and sputum produced significantly higher levels of elastase than those from other infection sites $(\mathrm{p}<0.05)$.

Amongst blood-culture isolates, those causing $100 \%$ mortality tended to produce higher levels of one or more exoenzymes than those causing zero mortality (fig. 3). In particular, strains B13 and B15 produced 


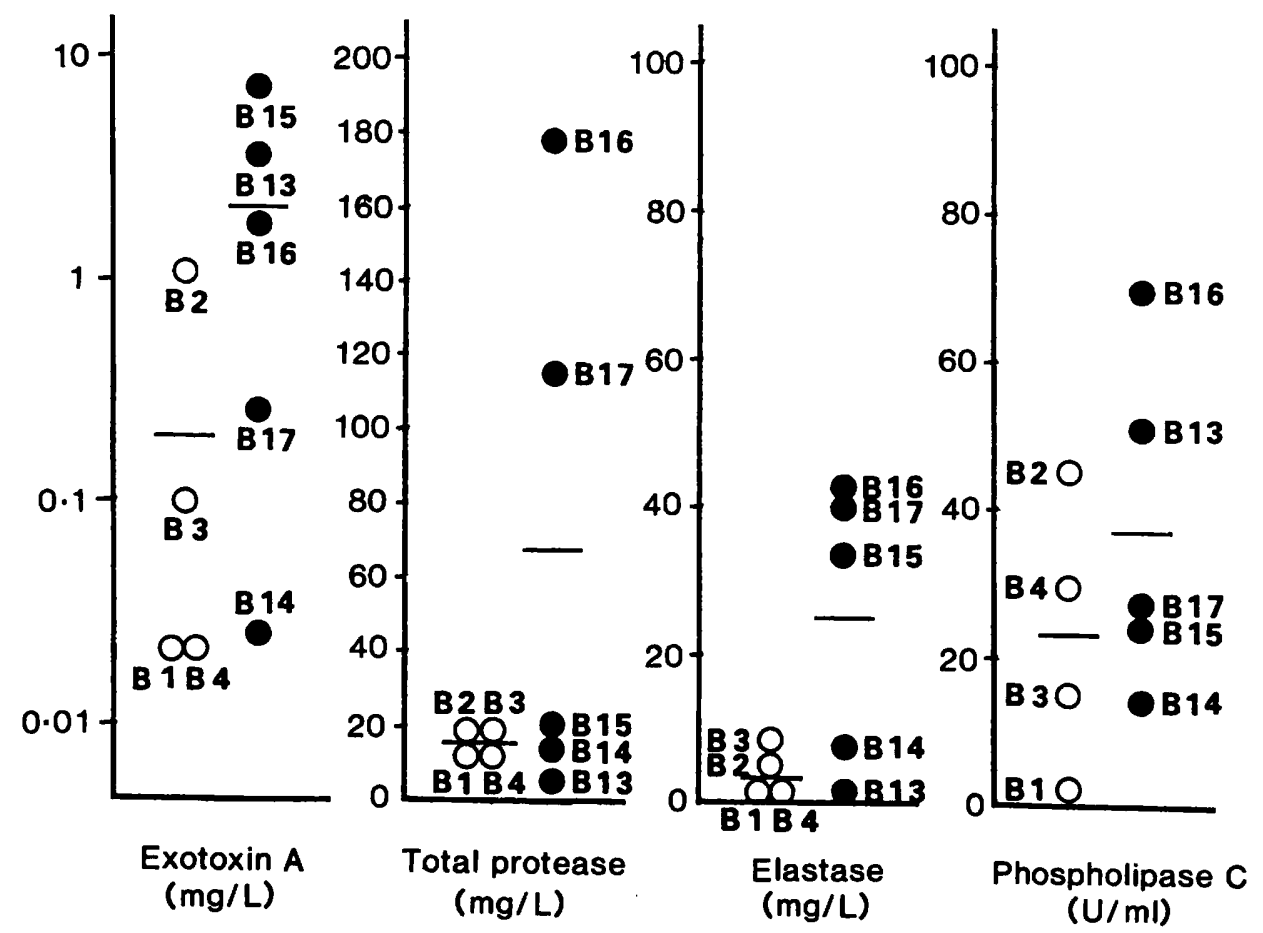

Fig. 3. Comparison of extracellular enzyme production between blood isolates of $P$. aeruginosa causing $100 \%$ mortality in mice with experimental endogenous septicaemia $(O)$ and isolates causing $0 \%$ mortality $(O)$. Bars indicate the mean enzyme production levels within each group.

high levels of exotoxin A and strain B16 produced all four exo-enzymes copiously. However, strain B14 gave $100 \%$ mortality yet produced relatively low levels of the exo-enzymes examined (fig. 3).

The serotypes of the isolates were not related to sites of isolation, mortality rates in mice, numbers of faecal bacteria or exo-enzyme levels.

\section{Discussion}

$P$. aeruginosa is frequently responsible for septicaemia in patients with malignant diseases, particularly leukaemic patients undergoing chemotherapy. ${ }^{4,20}$ Intestinal colonisation rates with $P$. aeruginosa have been reported as $>50 \%$ amongst patients with leukaemia, $20 \%$ amongst those with solid tumours, and $6-12 \%$ amongst healthy adults. ${ }^{21}$ Tancrède and Andremont ${ }^{4}$ showed that $81 \%$ of patients with bacteraemia caused by $P$. aeruginos $a$ were intestinal carriers of the same strain. These data suggest that the $P$. aeruginosa strains causing septicaemia in patients with malignant diseases frequently originate from the intestinal flora. Routes of acquisition of $P$. aeruginosa include patient-patient or staff-to-patient contact, water, food and disinfectants, ${ }^{3,22}$ but often remain uncertain. In many cases, the patient may have been colonised before admission with small numbers of $P$. aeruginosa. ${ }^{21}$ Factors that promote development of endogenous septicaemia include bacterial colonisation and overgrowth in the intestine, compromised immune defences and disruption of the mucosal epithelium. ${ }^{23}$

In the present study, an experimental model of endogenous septicaemia was developed. This model used oral inoculation of the bacteria to mimic the pathophysiology of septicaemia in man. In this model, $P$. aeruginosa strains isolated from blood cultures frequently caused septicaemia, whilst isolates from other sites did not do so. Moreover, blood isolates mostly persisted longer in the gut than those from other sources. These results suggest that blood isolates may carry additional virulence factors that assist colonisation, invasion, or resistance to host defences.

$P$. aeruginosa exo-enzymes may contribute to corneal damage associated with ocular infections and haemorrhagic and necrotic changes in the skin and internal organs, ${ }^{10,23-28}$ but their contribution in septicaemia is still unclear. Therefore, we examined whether the ability of $P$. aeruginosa to produce exoenzymes in vitro was related to the mortality rates amongst mice with endogenous septicaemia.

The results indicated that $P$. aeruginosa isolates from blood tended to produce higher levels of exotoxin $A$ and total protease in vitro than isolates from other infection sites. These data suggested that exotoxin A and total protease may be important exo-enzymes in the development of endogenous septicaemia. Nevertheless, correlation was not total and strain B14 caused $100 \%$ mortality despite minimal production of these exo-enzymes. Similarly, amongst blood isolates causing mortality rates between 10 and $90 \%$, some that were highly virulent formed little of the exo-enzymes in vitro whereas others that gave low mortality formed relatively higher levels. Further studies with mutant strains will help to understand the role of individual exo-enzymes in septicaemia.

In conclusion, some differences were demonstrated between $P$. aeruginosa strains that caused endogenous 
septicaemia with high mortality rates and those causing no septicaemia, with respect to the production of exo-enzymes and the ability of the bacteria to survive within the intestinal tract. Exotoxin A and total proteases may play some role in the pathogenesis of endogenous septicaemia; but it is necessary to examine

\section{References}

1. Kreger BE, Craven DE, McCabe WR. Gram-negative bacteremia. IV. Re-evaluation of clinical features and treatment in 612 Patients. Am J Med 1980; 68: 344-355.

2. Pizzo PA, Young LS. Limitations of current antimicrobial therapy in the immunosuppressed host: looking at both sides of the coin. Am J Med 1984; 76 Suppl 3A: 101-110.

3. Schimpff SC, Young VM, Green WH et al. Origin of infection in acute nonlymphocytic leukemia. Ann Intern Med 1972; 77: 707-714

4. Tancrède $\mathrm{CH}$, Andremont AO. Bacterial translocation and gram-negative bacteraemia in patients with hematological malignancies. J Infect Dis 1979; 152: 99-103.

5. Baltch AL, Griffin PE. Pseudomonas aeruginosa bacteremia; a clinical study of 75 patients. Am J Med Sci 1977; 274 119-129.

6. Pollack M, Young LS. Protective activity of antibodies to exotoxin A and lipopolysaccharide at the onset of Pseudomonas aeruginosa septicaemia in man. J Clin Invest 1979; 63: 276-286.

7. Hirakata $\mathrm{Y}$, Tomono $\mathrm{K}$, Tateda $\mathrm{K}$ et al. Role of bacterial association with Kupffer cells in occurrence of endogenous systemic bacteraemia. Infect Immun 1991; 59: 289-294.

8. Bjorn MJ, Vasil ML, Sadoff JC, Iglewski BH. Incidence of exotoxin production by Pseudomonas species. Infect Immun $1977 ; 16: 362-366$

9. Cross AS, Sadoff JC, Iglewski BH, Sokol PA. Evidence for the role of toxin A in the pathogenesis of infection with Pseudomonas aeruginosa in humans. J Infect Dis 1980; 14: $538-546$.

10. Liu PV. Extracellular toxins of Pseudomonas aeruginosa. $J$ Infect Dis 1974; 130 Suppl: 94-99.

11. Cryz SJ, Iglewski BH. Production of alkaline protease by Pseudomonas aeruginosa. J Clin Microbiol 1980; 12: 131-133.

12. Collins HH, Cross AS, Dobek A, Opal SM, McClain JB, Sadoff JC. Oral ciprofloxacin and a monoclonal antibody to lipopolysaccharide protect leukopenic rats from letha infection with Pseudomonas aeruginosa. J Infect Dis 1989 159: 1073-1082.

13. Hirakata Y, Kaku M, Tomono K et al. Efficacy of erythromycin lactobionate for treating Pseudomonas aeruginosa bacteremia in mice. Antimicrob Agents Chemother 1992; 36: 1198-1203

14. Bjorn MJ, Sokol PA, Iglewski BH. Influence of iron on yields of extracellular products in Pseudomonas aeruginosa cultures. $J$ Bacteriol 1979; 138: 193-200. the multifactorial nature of $P$. aeruginosa pathogenesis since virulence did not seem to depend on any single determinant studied.

We thank T. Usui and K. Hara for helpful suggestions, A. Saito, S. Kuwahara and S. Goto for critical comments, and K. Sugahara and C. Mochida for technical expertise.

15. Iglewski BH, Sadoff JC. Toxin inhibitors of protein synthesis production, purification, and assay of Pseudomonas aeruginosa toxin A. Methods Enzymol 1979; 60: 780-793.

16. Hirakata Y, Kaku M, Mizukane R et al. Potential effects of erythromycin on host defence systems and virulence of Pseudomonas aeruginosa. Antimicrob Agents Chemother $1992 ; 36$ : 1922-1927.

17. Woods DE, Schaffer MS, Rabin HR, Campbell GD, Sokol PA. Phenotypic comparison of Pseudomonas aeruginosa strains isolated from a variety of clinical sites. $J$ Clin Microbiol 1986; 24: 260-264.

18. Stinson MW, Hayden C. Secretion of phospholipase $\mathrm{C}$ by Pseudomonas aeruginosa. Infect Immun 1979; 25: 558-564.

19. Berka RM, Gray GL, Vasil ML. Studies of phospholipase C (heat-labile hemolysin) in Pseudomonas aeruginosa. Infect Immun 1981 ; 34: 1071-1074.

20. Richet H, Escande MC, Marie JP, Zittoun R, Lagrange PH. Epidemic Pseudomonas aeruginosa serotype 016 bacteremia in hematology-oncology patients. $J$ Clin Microbiol 1989; 27: 1992-1996.

21. Griffith SJ, Nathan C, Selander RK et al. The epidemiology of Pseudomonas aeruginosa in oncology patients in a general hospital. J Infect Dis 1989; 160: 1030-1036.

22. Correa CMC, Tibana A, Gontijo Filho PP. Vegetables as a source of infection with Pseudomonas aeruginosa in a university and oncology hospital of Rio de Janeiro. $J$ Hosp Infect 1991; 18: 301-306.

23. Jackson RJ, Smith SD, Wadowsky RM, DePudyt L, Rowe MI The effect of $E$. coli virulence on bacterial translocation and systemic sepsis in the neonatal rabbit model. $J$ Pediatr Surg 1991; 26: 483-486.

24. Gerke JR, Magliocco MV. Experimental Pseudomonas aeruginosa infection of the mouse cornea. Infect Immun 1971; 3: 209-216.

25. Iglewski BH, Burns RP, Gipson IK. Pathogenesis of corneal damage from Pseudomonas exotoxin A. Invest Ophthalmol Vis Sci 1977; 16: 73-76.

26. Kreger AS, Griffin OK. Physicochemical fractionation of extracellular cornea-damaging proteases of Pseudomonas aeruginosa. Infect Immun 1974; 9: 828-834.

27. Ohman DE, Burns RP, Iglewski BH. Corneal infections in mice with toxin A and elastase mutant of Pseudomonas aeruginosa. J Infect Dis 1980; 142: 547-555.

28. Tillotson JR, Lerner AM. Characteristics of non-bacteremic pseudomonas pneumonia. Ann Intern Med 1968; 68: 295-307. 